\title{
Factors Affecting Sexual Satisfaction in Iranian Women
}

\author{
Effat Merghati Khoei ${ }^{1}$; Raziyeh Maasoumi ${ }^{1, *}$; Solmaz Talebi ${ }^{2}$; Saiedeh Hajimirzaie ${ }^{3}$; Alireza \\ Bayat ${ }^{1}$; Shahnaz Rimaz ${ }^{4}$; Fatemeh Hirmandi ${ }^{1}$; Soraya Lotfi $^{1}$ \\ ${ }_{1}^{1}$ Brain and Spinal Cord Injury Research Center, Imam Khomeini Hospital, Neuroscience Institute, Tehran University of Medical Sciences, Tehran, IR Iran \\ 2 Department of Biostatistics and Epidemiology, Tehran University of Medical Sciences, Tehran, IR Iran \\ 3 Department of Midwifery and Reproductive Health, Faculty of Medical Sciences, Tarbiat Modarres University, Tehran, IR Iran \\ ${ }^{4}$ Department of Epidemiology, School of Public Health, Iran University of Medical Sciences, Tehran, IR Iran \\ ${ }^{*}$ Corresponding author: Raziyeh Maasoumi, Brain and Spinal Cord Injury Research Center, Imam Khomeini Hospital, Neuroscience Institute, Tehran University of Medical Sciences, \\ P. O. Box: 1419733141, Tehran, IR Iran. Tel: +98-216658156061, Fax:+98-2166938885, E-mail:r_masoumi@razi.tums.ac.ir; r_masoomie@gmail.com
}

Received: January 8, 2015; Accepted: June 22, 2015

\begin{abstract}
Background: Sexual satisfaction is a desired feeling that one experiences during sexual interaction and is affected by several factors.
Objectives: This study was conducted to examine the sexual satisfaction and its correlates among married women.

Patients and Methods: This cross-sectional study comprised 306 married women in their reproductive age, selected by convenience sampling method, and referred to the four health centers affiliated to Tehran University of Medical Sciences in 2012, the participants completed a researcher-made questionnaire. Statistical analysis was carried out using independent samples T-test, Chi-square and logistic regression through SPSS version 16.

Results: The mean score of the sexual satisfaction was $77.97 \pm 1.38$. Based on the mean, women were divided into two groups: sexually satisfied and dissatisfied. The Two groups matched in terms of age $(P=0.35)$, age of the husbands $(P=0.26)$, income status $(P=0.43)$, number of children $(\mathrm{P}=0.44)$ and contraceptive methods $(\mathrm{P}=0.13)$. Participants' educational level, menstrual status, marital duration, sexual function, husband's educational status and emotional bound were entered into the logistic regression model. Emotional bound had a significant effect on sexual satisfaction $(\mathrm{P}=0.04, \mathrm{OR}=1.54, \mathrm{CI}=1.01-2.36)$.

Conclusions: Emotional bound as a considerable trait is associated with women's sexual satisfaction. It is recommended that health care providers pay more attention to this point at the time of health care delivery and also to emphasize the renovation of interpersonal relationship.
\end{abstract}

Keywords: Sexual Satisfaction; Iranian Woman; Reproductive Age

\section{Background}

Sexual satisfaction is defined as emotional responses to sexual interactions; awareness and expressing sexual needs and desire, providing own or partner expectations and generally positive assessment of sexual relationship (1). In the viewpoint of Young, sexual satisfaction is a desired feeling that one experiences during sexual interaction (2). Any failure to achieve it will lead to many problems including marital conflicts which account for a substantial percentage of the couple's problems (3). The literature shows that sexual dissatisfaction is one of the main and assessable reasons for problems in the fields of mental disorders and increase in the rates of divorce and infidelity. According to the census organization's statistics, the number of marriages recorded in the first seven months of 2011 increased by $2 \%$ compared to the same period in the last census. However, the number of divorces increased by $10 \%$. Several reasons have been suggested to explain this situation, of which one possible hypothesis is the couples' sexual problems (4). Hence, identification of factors affecting sexual satisfaction in addition to strengthening the interpersonal relationship, play important roles in the stability of the family system (5). These factors include socio-demographic characteristics, socio-religious beliefs, socio-economic status (6), social support and family relationships (7), diseases, depression, psychic stress, drug usage, infertility, pregnancy, delivery (8) and use of contraceptive methods (9).

Sexual interaction is an important determinant for the continuation and health of couples' relationship. So, satisfaction of sexual interactions, in addition to the prevention of sexual disorders, especially in women, is associated with a sense of marital life satisfaction and leads to improving the overall quality of life $(8,10)$.

\section{Objectives}

Regarding the importance of sexual satisfaction and different factors influencing it, this study was conducted to examine the sexual satisfaction and its correlates among married Iranian women.

Copyright (C) 2015, Health Policy Research Center, Shiraz University of Medical Sciences. This is an open-access article distributed under the terms of the Creative Commons Attribution-NonCommercial 4.0 International License (http://creativecommons.org/licenses/by-nc/4.0/) which permits copy and redistribute the material just in noncommercial usages, provided the original work is properly cited. 


\section{Patients and Methods}

In this cross-sectional study 306 married women were recruited using convenience sampling. As a subjective meaning, sexual satisfaction is a basic and universal phenomenon women do experience, so we assumed the generalizability of the findings regardless of the non-probability sampling. These women referred to four of the public health centers affiliated with Tehran University of Medical Sciences in order to receive health care and other services over a period of 10 month in 2012. These centers are located in the South, North, East and West of Tehran. The referrals from centers in the south, east, west and north included 95, 86,77 and 48 of 306 women, respectively. All women were recruited by the trained midwives during working days. Inclusion criteria were Iranian nationalities, reproductive age (15 - 45 years), married status, having sexual life for at least one year prior to the study, being literate, lacking any physical illness or undergoing treatment for a known psychological problems such as depression and other known mental and mood disorders. Exclusion criteria included pregnancy, infertility and history of chronic diseases such as diabetes, hypertension and rheumatoid arthritis, history of any benign, pre-malignant or malignant diseases of genital tract, use of tobacco, alcohol, cocaine and other narcotics, use of anticonvulsants, antipsychotics, serotonergic antidepressants and oral contraceptives. Data were collected by researcher-made questionnaire with five-point responses. The questionnaire included three parts; 1 ) sociodemographic (15 questions), 2) sexual response (10 questions) and 3) sexual satisfaction (21 questions). The validity of the questionnaire was approved by the expert panel. The internal consistency of the measure, was also in acceptable threshold (Cronbach's alpha $=0.81$.
Having briefed the subjects about the purpose of the study, informed written consents were obtained from them. The participants in the study then completed the questionnaire which included four parts consisting of demographic characteristics, reproductive history, sexual function status and sexual satisfaction. Data analysis was done using SPSS software version 16 with independent samples T-test, Chi-square and logistic regression. P-values $\leq 0.05$ were considered statistically significant.

\section{Results}

In all, 318 women were approached, of whom 306 agreed to complete the questionnaire. The main reason for refusal was the fact that 12 women did not like reporting their ideas about sexual life. The mean age of the subjects in this study was $27.38 \pm 4.8$ years and the mean age of their husbands was $31.21 \pm 5.2$ years. The mean score of sexual satisfaction in the study was $77.97 \pm 1.38$ with the lowest and the highest scores being 25 and 105, respectively. Based on this mean, the women were divided into two groups; sexually satisfied and dissatisfied with their socio-demographic characteristics shown in Table 1 . Of participants, 169 women $(57.48 \%)$ were in the sexually satisfied group and 124 (42.17\%) in the sexually dissatisfied group. Also, the overall mean score of participants' sexual function was $28.43 \pm 5.16$ with the lowest and the highest scores being 8 and 38, respectively. This mean in sexually satisfied group was 30.27 \pm 4.49 and $25.93 \pm 4.97$ in the sexually dissatisfied group. The results of the independent samples T-test showed that the sexually satisfied and dissatisfied women were different in terms of the sexual function $(\mathrm{P}<0.001)$.

\begin{tabular}{|c|c|c|c|}
\hline Variables & Sexually Satisfied Women & Sexually Dissatisfied Women & P Value \\
\hline Age & $24.81 \pm 5.8$ & $26.65 \pm 4.3$ & 0.35 \\
\hline Husband's age & $30.72 \pm 3.2$ & $31.35 \pm 3.7$ & 0.17 \\
\hline Economic status ${ }^{b}$ & & & 0.43 \\
\hline Good & $76(45)$ & $51(40.8)$ & \\
\hline Moderate & $67(39.6)$ & $46(36.8)$ & \\
\hline Poor & $9(5.3)$ & $10(8)$ & \\
\hline Number of Children & & & 0.44 \\
\hline 0 & $13(7.7)$ & $6(4.8)$ & \\
\hline 1 & $70(41.4)$ & $53(42.4)$ & \\
\hline 2 & $61(36.1)$ & $44(35.2)$ & \\
\hline $3 \geq$ & $24(14.2)$ & $21(16.8)$ & \\
\hline Contraceptive methods & & & 0.13 \\
\hline Natural method & $68(40.2)$ & $52(41.6)$ & \\
\hline Barrier method & $54(32)$ & $26(20.8)$ & \\
\hline Hormonal methods & $20(11.8)$ & $21(16.8)$ & \\
\hline IUD & $16(9.5)$ & $8(6.4)$ & \\
\hline Sterilization & $7(4.1)$ & $16(12.8)$ & \\
\hline
\end{tabular}


Merghati Khoei E et al.

\begin{tabular}{|c|c|c|c|c|c|}
\hline \multirow[t]{2}{*}{ Variables } & \multirow[t]{2}{*}{ Coefficient (B) } & \multirow[t]{2}{*}{ Odds Ratio } & \multicolumn{2}{|c|}{ 95\% CI } & \multirow[t]{2}{*}{ PValue } \\
\hline & & & Lower & Upper & \\
\hline \multicolumn{6}{|l|}{ Educational status } \\
\hline Illiterate & - & 1 & - & - & - \\
\hline Primary & -0.21 & 0.80 & 0.55 & 1.18 & 0.27 \\
\hline Secondary & 0.11 & 1.05 & 0.34 & 1.10 & 0.16 \\
\hline College & 0.78 & 1.40 & 0.75 & 1.01 & 0.33 \\
\hline \multicolumn{6}{|c|}{ Husband's Educational status } \\
\hline Illiterate & - & 1 & - & - & - \\
\hline Primary & -0.45 & 0.42 & 0.21 & 1.09 & 0.13 \\
\hline Secondary & 0.17 & 1.65 & 0.85 & 1.56 & 0.29 \\
\hline College & 0.69 & 1.02 & 0.64 & 1.27 & 0.44 \\
\hline \multicolumn{6}{|l|}{ Emotional Bound } \\
\hline Good & 0.43 & 1.54 & 1.01 & 2.36 & 0.04 \\
\hline Bad & - & 1 & - & - & - \\
\hline \multicolumn{6}{|l|}{ Menstrual status } \\
\hline Regular & -0.24 & 0.78 & 0.46 & 1.31 & 0.35 \\
\hline Irregular & 1 & - & - & - & - \\
\hline Marital duration & 0.05 & 1.05 & 0.86 & 1.29 & 0.59 \\
\hline Sexual Function & 0.01 & 1.01 & 0.96 & 1.06 & 0.62 \\
\hline
\end{tabular}

The results of the independent samples T-test and the Chi-square test indicated that the two groups matched in terms of age $(P=0.35)$, husband's age $(P=0.26)$, income status $(P=0.43)$, number of children $(P=0.44)$ and contraceptive methods $(\mathrm{P}=0.13)$.

Logistic regression was applied to identify the associated factors affecting sexual satisfaction. The results of this analysis are presented in Table 2 . From all variables including educational level, menstrual status of the subjects, marital duration, sexual function, husband's educational status and emotional bound analyzed by logistic regression model, emotional bound had a significant effect on the sexual satisfaction $(\mathrm{P}=0.04, \mathrm{OR}=1.54, \mathrm{CI}=1.01-2.36)$. It means that probably a good emotional bound would significantly increase the level of sexual satisfaction.

\section{Discussion}

Emotional bound as a considerable trait is associated with women's sexual satisfaction. It is recommended that health care providers pay more attention to this point at the time of health care delivery and also to emphasize the improvement of interpersonal relationship.

Results of this study showed that from all variables studied, emotional bound could increase the level of sexual satisfaction. So, this variable can be a predictive factor for women's sexual satisfaction. Although in this study, this feeling was not questioned in more detail, it appeared to be like the comment of Basson. This researcher showed that a woman may not have any sexual desire at the start of a sexual relationship, because her motivations for be- ginning a sexual intercourse are numerous and complicated. Basson believed that potential motivational factors in women include increased intimacy with sexual partner, feeling of attractiveness, feminineness, gratitude, love or loss of anxiety. While in men, strong association was observed between mental stimulation and erection, but this association was not seen in women and instead sexual arousal with increasing intensity in women emerges with thoughts and feelings following sexual excitement (11).

Although, other variables such as participant's educational level, menstrual status of the subjects, marital duration, sexual function, husband's educational status were not significantly recognized in this study, the review of the literature indicated that the educational level of the couple is an effective variable regarding sexual satisfaction. In the study of Barrientos that aimed to investigate the relationship between psychosocial variables and sexual satisfaction, education was one of the predictors of sexual satisfaction among women (6). This was in contrast to the results of the study by Rahmani et al. (12) who found no relationship between education and sexual satisfaction which is similar to the results of this study.

In this study, length of marriage had no impact on the women's sexual satisfaction which is inconsistent with the findings of Shahvari et al. (8) who reported higher sexual satisfaction of the couples with marital duration less than two years. However, in another Iranian study this variable was identified as 15 years (12). In contrast, Rainer and colleagues found that lengthy marriage was associated with decreased sexual satisfaction (13). Social 
construction and cultural models may have various explanations for this controversy.

Sexual function was another variable that can influence women's sexual satisfaction. Although, this variable was not significant in sexual satisfaction, the findings of related studies indicate the potential role of sexual function in the women's sexual satisfaction. The study of Hulbert (14) indicated the relationship between desire, arousal and orgasm and sexual satisfaction. In contrast, lack of desire, vaginal dryness, erectile dysfunction, inability to achieve orgasm and pain during intercourse are associated with lower sexual satisfaction (15). Furthermore, in the study of Haavio-Mannila and Kontula (16) which evaluated the factors associated with the increased sexual satisfaction, the number of sexual intercourses and the variety of sexual behaviors were associated with increased sexual satisfaction. This was in agreement with the results of study by Tavakol et al. (17) who aimed to evaluate the relationship between sexual function and sexual satisfaction where all variables related to women's sexual function including sexual behavior during the past one month, feeling wet, reaching orgasm, time of reaching orgasm were associated with sexual satisfaction.

In some studies such as Larson's investigation, menstrual status was a significant variable to predict women's sexual satisfaction. Larson et al. (18) study aimed to evaluate the changes in women's feelings about romantic relationships across the ovulatory cycle, which showed that women's feelings about their long-term relationships change across the menstrual cycle. This indicates the important role of change in the reproductive hormones of women in the dynamics of romantic relationship throughout the cycle. Therefore, it is possible that in the sexually satisfied women with more regular menstruation, regular changes in reproductive hormones cause better emotions and feelings towards husband, a condition associated with higher levels of sexual satisfaction.

This study had some limitation. Firstly, the age range of the participants in this study was confined to reproductive period and excluded pregnant and postmenopausal women. However, the reason for this sampling bias was due to a definitive difference in sexual status during reproductive ages, pregnancy and post menopause among Iranian women (19-21). Secondly, the findings from convenience sampling may not be strong enough to predict factors affecting women's sexual satisfaction. Thus, the cluster random sampling is suggested to achieve this goal.

\section{Acknowledgements}

We would like to appreciate the valuable cooperation of the women who participated in this study.

\section{Authors' Contributions}

Effat Merghati Khoei designed the research and revised the manuscript. Raziyeh Maasoumi contributed to the data analysis and revised the final manuscript. Solmaz
Talebi contributed in analyzing the data. Saiedeh Hajimirzaie organized the data and wrote the primary manuscript. Shahnaz Rimaz revised the manuscript. Alireza Bayat, Fatemeh Hirmandi and Soraya Lotfi contributed to the data collection phase and data entry.

\section{References}

1. Klapilova K, Brody S, Krejcova L, Husarova B, Binter J. Sexual satisfaction, sexual compatibility, and relationship adjustment in couples: the role of sexual behaviors, orgasm, and men's discernment of women's intercourse orgasm. J Sex Med. 2015;12(3):667-75.

2. Young M, Denny G, Young T, Luquis R. Sexual satisfaction among married women age 50 and older. Psychol Rep. 2000;86(3 Pt 2):1107-22.

3. Afshar M, Mohammad-Alizadeh-Charandabi S, Merghti-Khoei ES, Yavarikia P. The effect of sex education on the sexual function of women in the first half of pregnancy: a randomized controlled trial. J Caring Sci. 2012;1(4):173-81.

4. Honar Parvaran N, Tabrizi M, Navabi Nezhad S, Shafi Abadi A. Efficacy of emotion-focused couple therapy training with regard to increasing sexual satisfaction among couples. Thought Behav Clin Psychol Rep. 2010;4(15):59-70.

5. Ziaee T, Jannati Y, Mobasheri E, Taghavi T, Abdollahi H, Modanloo M, et al. The Relationship between Marital and Sexual Satisfaction among Married Women Employees at Golestan University of Medical Sciences, Iran. Iran J Psychiatry Behav Sci. 2014;8(2):44-51.

6. Barrientos JE, Paez D. Psychosocial variables of sexual satisfaction in Chile. J Sex Marital Ther. 2006;32(5):351-68.

7. Henderson AW, Lehavot K, Simoni JM. Ecological models of sexual satisfaction among lesbian/bisexual and heterosexual women. Arch Sex Behav. 2009;38(1):50-65.

8. Shahvari Z, Qolizade L, Mohamad Hossein S. [Factors associated with the sexual satisfaction of women]. J Gorgan Univ Med Sci. 2009;11(4):51-3.

9. Li RH, Lo SS, Teh DK, Tong NC, Tsui MH, Cheung KB, et al. Impact of common contraceptive methods on quality of life and sexual function in Hong Kong Chinese women. Contraception. 2004;70(6):474-82

10. Propper S, Brown RA. Moral reasoning, parental sex attitudes, and sex guilt in female college students. Arch Sex Behav. 1986;15(4):331-40.

11. Basson R. Women's sexual dysfunction: revised and expanded definitions. CMAJ. 2005;172(10):1327-33.

12. Rahmani A, Sadeghi N, Qoli L, Merghati Khoei E. [Individual factors associated with sexual satisfaction in couples]. J Nurs. 2010;23(66):14-22.

13. Rainer H, Smith I. Education, Communication and Wellbeing: An Application to Sexual Satisfaction. Kyklos. 2012;65(4):581-98.

14. Hurlbert DF, Apt C, Rabehl SM. Key variables to understanding female sexual satisfaction: an examination of women in nondistressed marriages. J Sex Marital Ther. 1993;19(2):154-65.

15. McQuillan SK, Grover SR. Systematic review of sexual function and satisfaction following the management of vaginal agenesis. Int Urogynecol J. 2014;25(10):1313-20.

16. Haavio-Mannila E, Kontula O. Correlates of increased sexual satisfaction. Arch Sex Behav.1997;26(4):399-419.

17. Tavakol Z, Myrmvlayy T, Momenimovahed Z, Mansouri A. Investigate the association between sexual function and sexual satisfaction in women referred to health centers in southern Tehran. . Sci J Hamadan Nurs Midwifery Faculty. 2011;19(2):36.

18. Larson CM, Haselton MG, Gildersleeve KA, Pillsworth EG. Changes in women's feelings about their romantic relationships across the ovulatory cycle. Horm Behav. 2013;63(1):128-35.

19. Brtnicka H, Weiss P, Zverina J. Human sexuality during pregnancy and the postpartum period. Bratisl Lek Listy.2009;110(7):427-31.

20. Shirvani MA, Nesami MB, Bavand M. Maternal sexuality after child birth among Iranian women. PakJ Biol Sci. 2010;13(8):385-9.

21. Trutnovsky G, Haas J, Lang U, Petru E. Women's perception of sexuality during pregnancy and after birth. Aust N Z J Obstet Gynaecol. 2006;46(4):282-7. 